\title{
What isn't the Mangerial Decision? A Different Point of View on the Most Important Activity of a Manager
}

Ionuț-Dacian CEHAN ${ }^{1}$

\begin{abstract}
The managerial decision is the most important tool of a manager, being present day after day in his organizational work and having direct effect on both organization and employees. The managerial decision may be seen from different points of view, starting with the manager's perspective, then with organizational strategy and employees' view. The managerial decision is the most important in an organization, being a process that involves more stages, one of them being human relations; the managerial decision may be seen through the lens of different points of view. In this article it is offered a perspective on the managerial decision, by highlighting the uncommon aspects and by denying those that are not his own. The paper objective is to highlight the essence of managerial decision, by showing in fact what it is not.
\end{abstract}

Keywords: managerial decision, author's perspectives, manager, processes.

JEL: M111, L1, M12, M15

DOI: $10.24818 / \mathrm{RMCI} .2018 .4 .403$

\section{Introduction}

The managerial decision represents a challenge for every researcher who wants to understand the whole mechanism. The whole decisional process is represented by several steps that the manager must follow to make the right decision under the given circumstances.

Presenting the managerial decision as what it isn't, from a different point of view means explaining more about it than presenting it affirmatively. By presenting the managerial decision as what it is not, what is doesn't represent and by what it does not mean, it can advise on more aspects as opposed to presenting what it actually is. It is an interesting perspective and at the same time useful in studying the most important activity of a manager in an organization. By presenting the negative aspects of the missing traits in comparison with what the decision is lacking, brings a new perspective on the managerial decision and on what it represents. If we can affirm it by seeing it negatively then the new perspective we created can be much more interesting than the usual assumptions, aspects and qualities. Considering all this about the managerial decision and presenting it as what it is not, we will offer a new perspective on it.

\footnotetext{
1 Ionuț-Dacian Cehan, PhD Student, Faculty of Textiles, Leather and Industrial Management "Gheorghe Asachi” Technical University of Iasi, Romania, Email:ionut_cehan@yahoo.com
} 


\section{Statement of the Problem}

Therefore, what it isn't the managerial decision?

\subsection{The Managerial Decision is not Like any other Decision}

What customizes the managerial decision is bound by the essence of it, the way that it has been made, by the decision maker and by the pursued objectives (Bonci, 2014). First of all, the managerial decision it is made in a certain organizational environment, that implies more than a common one, outside of the organization. Related to this, we should mention that the managerial decision starts as a result of rising of a problem, that is discussed and analyzed. Secondly the managerial decision assumes a path that should be followed for reaching its final point. The decisional process is built from different activities that deal with the information, the discussion of the possible choices and then the best one is chosen and subsequently implemented. Also the decisional process requires some steps (according to some authors, four after other authors six or seven). A decision-making process can take the following steps: preparing the decision, adopting it, implementing it, and ultimately evaluating it or the changes that it may cause. No decision, apart from the managerial one, knows these stages. The managerial decision is distinctive, being taken by a decision-maker, the one who is specifically asked to make decisions. The decision-maker is the person who, through the role of his / her function, makes the necessary decisions for the management, for the smooth functioning, and objectives of the organization. If a manager should be defined by two terms, then the most appropriate would be to lead and to decide. The manager can often be associated with the decisions he takes, and his decision tells something about his personality, about what he is. There is also what Stewart (Stewart, 1996) says about the manager's decision when he uncovers it at the heart of each leader. Therefore, the managerial decision cannot be compared to any other decision, because, by its peculiarities, it differs from any other decision. Even a decision taken by the manager outside the organization will be different from any decision taken inside the organization.

\subsection{The Managerial Decision is not a Form of Manifestation of Authority}

Certainly, the managerial decision must not be a way for the manager to manifest his or her authority or power. Even if the manager holds the authority, which is a form of managerial power, the decision he takes within the organization must not be a form of expressing this authority. The role of the decision is to solve an issue, a problem that arises in the organization, and this must not result in the use of the power of the manager, of the authority with which he is endowed. It is good for the manager to discern between the power he has within the organization and the decision he makes for its smooth functioning, otherwise unnecessary problems may arise. When making a decision, the goal of the manager is not to use his authority, to

$404 \quad$ Review of International Comparative Management

Volume 19, Issue 4, October 2018 
show that he has it or to use it. Certainly, there are cases that could confirm such behaviors that are not desirable in the organization, when the manager uses the utmost authority to make the decision he considers best regardless of whether it proves to be the most appropriate, or can even affect the employees.

\subsection{The Managerial Decision is not a Simple Statement}

Often, what is behind a manager's decision is not perceived, known or understood. Even if a manager's decision can only sound like a simple assertion, however, what is behind the decision is necessary to be known and respected. There are many factors involved in making and adopting a decision. below:

At a glance of these factors, we can mention a few categories, presented

- Organizational factors - of these we can mention: the organizational strategy, the proposed objectives, the human resources, the financial resources.

- Factors related to the managers own personality. One of the best known factors in this respect is past experience (Juliusson, Karlsson et all, 2005), the cognitive abilities of the decision-maker ((Finucane, Mertz, et all, 2005), the age (Finucane, Mertz, et all, 2005), personal interests (Acevedo and Krueger, 2004).

- Psychosocial factors. Psychosocial factors have been seen as the group of factors that offer a response to the constraints of the external environment (Schnittker, 2004). They are only part of the psychosocial factors, and have a special role to play because they directly influence the human personalit. The psychosocial factors are present in people's daily lives, them being more or less aware of their presence and action. They can also cause changes in the behavior of the individual, affecting him, his attitude, his perception of a particular object or event; it can explain the adherence to a social group, what an individual is doing in a particular situation, it can provide data on human health and can add to the knowledge of the human personality, and it can also provide explanations that can not be found in other areas or offer a profound understanding of what is being researched. Looking through the lens of the psychosocial factors, what happens to the individual and what he does acquires a new meaning and brings new explanations and clarifications, but also offers a perspective that cannot be understood without studying them.

Even though it takes the form of a simple statement, of a simple assertion, what lies behind the decision gives a completely different perspective on it. A profound insight into the managerial decision shows that it is imperative to view the decision as an assertion, which was built on the basis of experiences and under the influence of several factors presented above.

\subsection{The Managerial Decision is not a Simple Choice}

Even if it takes the form of a statement, the managerial decision is not a simple choice, but a choice that has to take into account several aspects (Natale et all 1995): Therefore, a manager will not seek a simple choice, but the best choice he can make at that time with the resources at his disposal, taking into account the goals he 
has to accomplish. One of the stages of the decision-making process is choosing the optimal option after everything has been analyzed. It is perhaps the most important stage, which requires the manager's experience, his qualities, as well as the responsibility he has for what he chooses. After searching for information and after everything has been discussed it is time for the manager to make a rational choice and to assume his responsibility of the choice he made regarding the given problem. It is the stage where the best solution (or alternative) is selected to move on to action. The managerial decision should therefore be seen as a choice from several points of view, this being the best solution found by the manager at the time, under the given circumstances, and with the available resources. On the other hand, managerial decision is a choice that is assumed by the manager because he will answer for the choice made. At the same time, he must take on his decision, and if asked to justify it, he must do so. All these aspects reinforce the above statement, pointing out that, if viewed as a mere choice, the managerial decision would lose its essence and importance, which means that it can no longer be considered as the essence of Management.

Also, managerial decision should be seen as a responsible, correct choice, a wrong choice, can endanger both the organization and the employees. (Filip and Iamandi, 2012, p.9).

\subsection{The Managerial Decision isn't the Answer to only one Simple Question}

Making a managerial decision means going through several stages, as shown before, each stage being composed of going through many questions, through each filter, and in the end, finding the answer to those questions. There are few examples of those questions that represent this aspect, of multiple questions that consists taking a decision. What is the problem? What is the problem related to? How should the decision be implemented? What is the best way? On the road of making a decision, the question asked has to be about finding the best approach to the problem, overcoming the obstacles that could rise up and being prepared for the changes that could take place. In this case, the managerial decision cannot be limited to one answer to a question, as in its final form it has to be the answer to all of the questions that surrounds it, even if, in the beginning it all started from one question.

\subsection{The Managerial Decision is not just one act, Consisted of one Actor}

Even if it is specific to the manager, the managerial decision should be looked at as a process which involves not just the manager, but the human resource of the organization. If we look at the events that take place in an organization, we can surely see that the managerial decision isn't just a singular act (Cucer, 2013). Looking from a large spectrum, the decision belongs to the manager, but, if we were to look at it from a relationship perspective, the decision gets a different meaning, a relationship, which surely involves the society. All in all, the managerial decision can be looked at from a social perspective. An argument that stands at the base of 
this affirmation is the presence of the decision maker and the executor in the decision-making process. An adopted managerial decision has to be, in the end, applied and executed by the employees, or by the people that were specifically hired for this aspect. On the other hand, when the manager chooses a person to make decisions in his name, this represents, again, proof that a decision involves social relationships. This involves having a good knowledge of others personalities, of passing the power, of trust, of something so personal to the manager, a different positioning regarding everything that was normal until then. For example, a manager can let a subordinate decide from several variants, or, after assigning him to a certain job, he lets him choose the best approach in order to realize it. The most important thing is, that in the moment he chooses to do that, the manager takes responsibility for the decision that the subordinate has taken. That's why, a manager need to have a better knowledge not only of the domain that he works in, but also in the art of knowing people, in discovering the assets that the subordinates have. He is also the one that, in case the decision is bad, has to intervene and correct the situation.

To be able to choose the right person, the manager has to have the following requirements:

- Have knowledge in the psychology of personality - knowing the subordinates that he entrusts with the decision making mentally, interrelationally, etc.;

- Have knowledge in the organizational psychology - to establish what links are needed, and to know to what extent he can grant this privilege to an employee;

- The way he formulates the requirement - it requires some skill in the art of words, to communicate as clearly as possible what is to be decided by the one to whom it is entrusted. Also, he does not have to feel constrained or threatened in case of failure;

- Empathy to whom he entrusts this task;

- Awareness to the entire decision-making process, without which, one can reach what is undesirable;

- Collaboration, which implies such delegation, is a different kind of cooperation than the usual one. The manager sees himself in a position to entrust his own power to another person, which places him bellow that person, and it requires acceptance, patience, meditation etc

About the involvement of social relations in decision-making, Vroom (Vroom, 1986) presented five management decision styles in solving problems:

- Solving the problem according to the manager's knowledge;

- Getting information from the employees, then the manager decides on his own decision;

- Having one on one talks with the subordinates, then discussing the problem together. The manager makes the decision he thinks it's best;

- Discussing the problem with his subordinates, after which the manager makes a decision, even if it could be or not their solution; 
- Discussing the problem with his employees and finding solutions; the manager is willing to accept the solutions offered by his employees

Most of these variants involve relationships, orientation towards the other, joint work, managerial decision, being understood as a joint action, not just manager but involving more actors.

\subsection{The Managerial Decision is not, in the End, a Simple Process}

As stated above, the managerial decision cannot be summed up as a simple process, without being linked to all the events and actions that it involves, and the factors involved in its taking. If it is not a simple process, managerial decision can be regarded as a complex process, which, in addition to taking several steps, does not depend only on the qualifications of the manager, his qualities but also his resources, the characteristics of the problem that appeared, etc. If it were a simple process, the manager's decision would not have such an important role in the organization. However, managerial decision plays the central role in the organization, which means simply adopting it will mean diminishing the importance it has. This is why the manager's decision should not be seen as a simple process, although sometimes in the form of a simple statement, it can be perceived as a simple, uncomplicated process. What lies behind the managerial decision tells everything about its complexity. Often these aspects are not observable. It is also the case with mental processes, which can be defining in the decision-making process.

\section{Conclusions}

Managerial decision is, in essence, the center of the organization, being the most important activity of the manager, the one that characterizes him most, and its adoption means, in the end, going through an entire process which, in most cases, cannot be looked at from the outside. When defining the managerial decision, the authors prefer to use different terms to highlight its essence as accurately as possible, and to capture as deeply as possible the phenomena that take place and the behaviors associated with the manager throughout the decision-making process. Of the terms that are used when a managerial decision is defined we can recall the following: central point, efficacy, link, essence, central place, adoption, action, etc (Baba, HakemZadeh, 2012). These examples are eloquent in defining the decision and understanding as a complex process. Managerial decision cannot be understood unless it is referred to terms as above or similar.

What was wanted in this article was to highlight the essence and characteristics of the managerial decision by affirming what is not, in other words, by bringing to the surface what cannot be the managerial decision. Through these simple statements formulated in negative form, it was attempted to provide a different perspective on the managerial decision that would conform to the definitions already known in the literature. Therefore, there was no attempt to present another perspective, but a point of view similar to that asserted by the authors of the literature. Therefore, the managerial decision has acquired a different meaning, and 
a new meaning. What is not the managerial decision shows about it, in fact, what it is, in essence. By comparison and negation, it was desired to draw a complex picture of what the manager's decision is. In formulating the seven points there were taken into account the most complex definitions of the managerial decision, the author's perspectives on the decision in the organization, and what he considered to be the most representative statements referring to the manager's decision.

This article presents not only an own perspective, but also a reformulation of assertions and perceptions of managerial decision found in literature. However, this article would like to emphasize the attributes of the manager's decision in a different way, leaving the reader to look and to formulate his own perspective on what the managerial decision may or may not be.

\section{References}

Acevedo, M. \& Krueger, JI. 2004. Two egocentric sources of the decision to vote: The voter's illusion and the belief in personal relevance, Political Psychology, 25(1), 115-134.

Baba, Vishwanatah V., Hakem Zadeh, Farimah, 2012. Toward a theory of evidence based decision making, Management decision, 5, 832-867.

Bonci, Cristian Dumitru, 2014. Decizia managerială - precizări conceptuale și terminologice, Revista de investigare a crimnalității, 2, 108.

Cucer, Angela, 2013. Note de curs la Psihologia personalității, Chișinău.

Filip, R. \& Iamanadi I. E., 2012, Management internaţional, suport de curs, București: Academia de Studii Economice din București.

Finucane, M.L., Mertz, C.K., Slovic, P. \& Schmidt, E.S. 2005. Task complexity and older adults' decision making competence. Psychology and Aging, 20(1), 71-84.

Juliusson, E. Ásgeir, Karlsson, Niklas \& Gärling, Tommy, 2005, Weighing the past and the future in decision making, European Journal of Cognitive Psychology, 17, 561-575.

Natale, S. M., Libertella, A. F., Rothschild, B. M., 1995. Decision-making process: the key to quality decision, American Jorunal of Management Development, $1,(4), 5-6$.

Schnittker, J., 2004. Psychological Factors as mechanisms for socioeconomic disparities in Health: a critical appraisal of four common factors. Spring Summer, 51 (1-2), 1-23.

Stewart, A. E. \& Stewart, E. A. 1996. Personal and practical considerations in selecting a psychology internship, Professional Psychology: Research and Practice, 27, 295-303.

Vroom, Victor, H., A new look at managerial decision making, "Readings in Management”, 1986, pp. 132-148 